\title{
Anton and Jay's Sports Trading Card Series: Embracing the Presence of Letters
}

\section{Lisa Schoenfielder}

On a crisp day in November Jay and Anton, two sixth grade boys, were the first off the school bus. The art room held five good sized work tables. Throughout the year the children in the gifted art program had been grouping themselves pnmarily by gender but also by shared interests. This year the five girls in class chose to crowd around one table. Soon after Jay and Anton arrived, others came and began transporting works in progress to their workspaces. At the girl's table. there was a partially constructed horse arena, some clay chickens that needed to be painted, a wooden wagon and the beginnings of a winter skating pond. The remaining nine boys tended to be distributed at the other four tables, grouped according to boys who liked animals and science, boys who liked vehicles and war scenes and boys who liked sports.

Jay and Anton were boys who liked sports. At the end of the school year I went to copy the series of home-made sports trading cards produced by Jay and Anton. The man behind the counter at the copy store wanted to know who had made the cards. He seemed surprised when I told him that the series of cards were the latest artistic endeavor of two sixth grade boys. "No kidding, two kids made all of these? These are better than the one's you buy." He picked up the Tim Hardaway card sitting on top of the pile and looked at it more closely. I noticed the similarity between this card of Anton's and the clean economical designs of Keith Haring's. Anton had outlined the figure using a thick yellow line and placed it against a deep blue background. There were yellow lines that radiated subtly around the figure as well. The outlined arms raised in the air reminded me of sunshine against a deep blue sky. I agreed with the store clerk. The two boys had produced a series of sports trading cards that were more vibrant than any I had seen come from the commercial card industry. I looked down at the array of cards noticing the luminosity the watercolor markers and fluorescent highlighters brought to the cards in comparison to commercial inks.

Upon their early arrival on that fall day, the boys headed straight for their table at the end of the room. Jay sat down. opened his pencil box and instantly remembered the promise I had made to him at the end of the last class. "Hey, did you get $\mathrm{em}^{\prime}$ ?" Jay asked sitting with his legs tucked tightly under the table and his neck twisted back around as far as physically possible toward where I was getting some supplies out of a storage cabinet. "Get what?" I teased. "Oh yeah, permanent markers," I said slowly, still pretending as though I might have forgotten them. Anton quickly caught on. "Nice try. Where are they?" I placed a black Sharpie Fine Point in each boy's hand. "You give me one and I'll give you three, "Jay said as he held out an open hand with three dried out fine point permanent black markers. Jay quickly retracted his hand as I reached for the markers but not before I noticed how the word Sanford and other letters on the plastic casing had partially worn away. Anton began to count out loud his empty markers, making sure that I was watching as he found and pulled each one out of 
the box. The fact that both Jay and Anton had saved these useless tools puzzled me. Were the used-up markers a trophy of sorts, a reminder of the weeks and months the two boys had put into making the series of sports trading cards?

The collection of dried out markers with the Sanford trademark worn away reminded me of the country and western singer Willie Nelson's favorite guitar that had a hole where the pick had worn through the wood over time or the clear spot that could be seen in the center of the tennis racket I used when I was in junior high school. The hole in the guitar, the sweet spot on the tennis racket where the strings wore thin and the saved empty markers are evidence of intense involvement and commitment to a particular activity.

When Jake and Andy began creating the series of home-made sports trading cards my initial instinct was to tell them they could not work on the cards in art class. The boys had collected pages from Sports Illustrated and other magazines. In class they sorted through their stockpile of images and began selecting ones to crop and fit onto $21 / 2$ " $\times 31 / 2$ " cards. Once a cut-out image had been pasted down the text and graphics were arranged in the white space that remained around the figure.

Perhaps the designs created around Jake and Andy's cut-out figures seemed too easily resolved, which explained my initial unease with what they would be doing in the class that met for two hours every other Monday throughout the school year. I wanted the children in the gifted art program to follow a path of inquiry that was personally satisfying. But, I hoped a balance could be struck between making art and learning art concepts. Unsure of what to do next, I waited and paid close attention to the unfolding of Jake and Andy's series of sports trading cards. By March, they had made over one hundred cards between them, and I began to notice their critical sense of appreciation for the subtlety and nuance of their growing artistic series.

Jay and Anton cultivated skilled thinking in an ongoing critique of their unfolding body of cards. As cards evolved over time the boys developed more sophisticated levels of connoisseurship. When they talked to me about their series I could understand the extent to which this project had allowed them to acquire ideas, skills and techniques for the purpose of making their cards. I noticed for instance, that the trading card series had led Jay and Anton to make refined distinctions in their use of graphic design.

"Anton look. Here was your first card," Jay reflected. "Oh yeah. Michael Jordon," Anton said, looking intently at the very first card he had made. A moment of silence passed as the boys looked at the card. "Hardly any writing." Anton finally pointed out to me breaking the silence. This first card of Anton's had a border within the perimeter of the card. The photographic image of Michael Jordon was a rectangle with one foot breaking out of the confines of the inside border, and one hand holding a basketball breaking out of the rectangle as well. The entire photograph, figure and background were intact and placed within the rectangular card. At a point in the series, the boys left the background out completely and focused exclusively on cutting out the contour of the figure. 
I could imagine that the commercial photo image with a part of the figure breakıng out of the confines of the picture space in Anton's first card was a precursor in some way to the boys freeing the figure from the environment in which it was initially set.

Compared to cards that came later in the series, Anton's first card showed less action because the figure was restricted by the rectangular format it was confined to in the photo image. Across the central rectangular image was a plain banner with Michael Jordon simply printed. The design and text did not interact with the same complexity and sophistication integral to cards that came later in the series. It was as if the photo image and the applied graphics existed on separate planes with one plane simply superimposed on top of another. When Anton looked at the card he said slowly, "Yeah, this is still a good card." It was as if he was telling himself that the card still had merit in spite of its simplistic features

Anton had since become a master at folding text and design in and around the photo images that had been perfectly cut and cropped to give the optimal eflect of action within the small rectangular cards. He stared blankly at his first card for a few seconds longer and then turned quickly to another Michael Jordon card for me to see. "Look at this Jordon. This is one of my favorites See how I did the Jordon and the Michael and everything. See the Jordan makes letters look like they move. I have about five different types of letters that I make." Anton pointed to examples as he named them:

Double letters. Autograph letters. That is just like writing. Letters written with colors around them like this Art Monk. Striped through letters like Emitt. Emitt Smith. This I don't know how to explain. I guess kind of a tall letter. Shadow letters. Little letters like this Lawrence Thunderbird. This kind of different slanted missile. There is another writing we really like. Fuzzy writing like around this Scottie Pippin. You put yellow down first and then you put color and you get like fuzz. I didn't really do this it just happened. It was an accident but it turned out really neat. Straight stripe. Slanted stripe. Oh yea and these dots between letters are kind of different. It kind of makes it look like you are spelling it or something. I don't know, I just do it for the fun of it. Here's one. Do you see how / wrote that? I put like a triangle and I really put it in a slant and it ended up writing it. See how it goes here, here, here, here, and then I put a little space for the $D$ and the $E$ and then all together its all one thing and here the end. It's all one - it's like one shape.

Anton exhibited a growing awareness of the plasticity of letters and how his could be used to produce particular effects. For instance, he described dots between letters as being like spelling out loud. Anton understood the way in which dots between lutters worked as short pauses, creating a rhythm much like spelling a word out loud. Letters had become more than signifiers of words that had meanings. His seemed to have crossed over to a point where letters became more than themselves, displaying particular abstract qualities. Anton had embraced the presence of letters. He could see them as the multi media artist

Marilyn Zurmuehlen's Working Papers In Art Education 1996-1997 
Warren Lehrer had, for their ability to "dart and swoop and blare and recede and curl up and pop out and undulate and zoom across" (Lehrer in Ingalls, 1996, p. B5) a surface. Letters to Anton had become forms with other functions such as movement or rhythm as he had pointed out to me.

Jay, like Anton, could not help but respond critically to the cards he had produced early in the series. Jay pointed to a card of Tony Gwyn and said, "This is one of my first ones. I don't really like it that much but a lot of people like this. They say it is really good but I think I could do better on it. I don't know. Maybe make the same masterblaster different and make a different background." I remembered Jay showing this card to other boys at his table one day in class They were impressed with his work. When Jay looked at this card he probably remembered the positive response he received and was not ready to give up the thought that he was, even then, a good artist. Yet he knew that the cards he could make now would be better. Jay looked at the somewhat shaky black printing that sat rather lifelessly on the surface of the page and thought about how he would now make the "Masterblaster" differently.

For Jay and Anton, "how" to make a card included improving on their own previously made cards. The trading card series, as the boys had devised the project, offered many chances to develop and correct what they did before. Continuing work on their series offered the reward of a steadily growing ability to make better cards. Each week Jay and Anton made a few more cards and their confidence and skill level grew. Anton proudly explained to me: "I give my mom or dad my whole notebook and I say pick one. Just pick any one in there and I'l make it into a card for you and then l just do it. "He paused and looked at me for a moment as if to make sure that I understood the significance of his statement. By telling me this story Anton was letting me know that he had acquired a level of confidence as a card-maker. A confidence rooted in combining letters and images in dozens of cards.

When Anton spoke about his use of color I was reminded again of the ways in which he seemed to have gained a rich understanding of complex art principles in the unfolding series. "This is supposed to be Roberto Aloman. Whoops, I spelled his name wrong but I like this electric blue around this one. I like it that he looks like he is moving pretty good. It looks like fire or something." The orange cast to the skin and face did indeed give the appearance of an orange and blue flame. Jay explained to me that orange and blue were the team colors that determined his use of color in a card but Anton went on to say more.

Sometimes I don't just use the team colors. One thing that I like using that kind of goes with anything is that bright yellow. That goes with anything that highlighter does. That goes good with any color. It's really nice it makes it stand out. But its almost like white sometimes on the white paye. And gray. Gray I use a lol. I use a lot of turquoise but gray is kind of a color - well it just works with anything because well it's just kind of almost white. On this page is one of my favorites. I like the way the colors all kind of fit together. That was super hard to do getting all the colors like that - you see them. 
Anton pointed to a background design of solid red marker placed next to a textured pinkish shape made with a red crayon. The pinkish color was obtained by letting the white of the paper show through. The monochromatic color scheme in whieh he had achieved a transition of dark to light was repeated in several cards. Many of the team colors were complementary colors. By using these contrasting colors over and over in cards, Anton became aware of how complementary colors act in relation to each other. As he searched for other colors to add to this complementary schema he discovered the way gray could be neutral and the way fluorescent yellow on a white page makes the white more neutral. At one point Anton learned how to make an edge without an outline.

This one here is the only card where l ever used just two colors. Kevin Johnson. This one here is kind of hard to figure out. I didn't really know how to do that cause this here was the last thing I did. [Anton points to the $V$ in Kevin where the purple and orange meet] There was orange on this side and purple on this side. And I thought, how am I going to do that' And then I thought, 'can I do that without getting in the colors?' And then I thought of splitting it ... I didn't use black markers between because then you couldn't read it. So then I just did that so they're not even touching. And I had to split that there too. And now his shoes are the thing that stands out the most.

It was Anton's intention to make an all purple and orange card. As he started the task he had assigned himself, he could not figure out how to do this without using black marker to delineate between shapes. In the course of making this card Anton figured out how to make an edge without outlining. He also noticed that while the purple and orange were pushing and pulling, advancing and receding, the white shoes came forward most dominantly. Pointing to particular cards, Anton spoke about his ability to achieve desired effects by his manipulation of letters, colors, shapes and compositional devices that he used. He had worked so extensively with color and other design elements that he came to know these concepts intuitively. Describing these principles of design to me in our conversation was a natural outcome of Anton knowing more intuitively subtle distinctions between qualities.

When it came time to begin a new card both Jay and Anton paged through magazines looking for images and ideas. I watched Jay one day go to his stock of stored images and find a photo of Shawn Kemp jumping toward the hoop. He carefully cut out the figure and pasted it down on white card stock. Next on white paper, Jay drew a circle about twice the size of Shawn Kemp's head. He cut out and pasted the large basketball shape on Kemp's fingertips that were reaching toward the hoop. The planet Saturn was drawn in orange marker behind the figure and the words "space," "Shawn," and "Kemp" were printed in yellow highlighter across the sides and bottom of the picture plane. Jay outlined the word space in lime green highlighter and then began coloring in a dal $\alpha$ I light sky behind the words and images. As he darkened the background the oversized basketball became like the moon. 
Anton talked about finding an image that gave him a similar idea for a background. "This Tim Raines is really good. I like that one a lot. I saw the picture of him jumping into the sky and I started to think the moon, he's jumping over the moon.' So I cut out a picture of the moon."

Both boys borrowed freely from commercially marketed cards and from each other. In another card, Jay drew clouds and a sky behind Dominque Wilkins slam dunking the basketball. Jay and Anton used the clouds and sky in several cards to exaggerate the heights to which many players could jump.

Jay and Anton would not simply copy from each other or from commercial cards that appealed to them. Rather, they would create cards of their own using themes and graphic devices found in commercial cards and other sources. Space and sky themes were used to exaggerate a sense of height. Radial line designs were used to indicate the explosive quality or the impact a player had on a situation. Both boys were drawn to the dynamic quality of designs that incorporated these themes in commercial cards. Anton described his attraction and use of the commercial packaging of a particular type of card:

There is this kind of football card called sky box. It's a new kind of card. And on the cover of the package they have this picture and it looks like he is breaking through. You cut that out and put that on a card and it looks like he is breaking through the card. Ijust kind of used this. When you buy a pack of cards the cover will have this. So l just kind of used it right off the pack cause it looks good like he is coming right out at you.

Jay's depiction of abstract shapes breaking the surface of the picture plane in his "Jackie Joyner Hershee" card was also a borrowed device to show the powerful force of movement created by the runner. Radial designs were appealing as a device that created movement. "See his (pitch) is faster than the speed of light," Jay said pointing to the radial star design behind Doc Goodin winding up for the pitch. Lightening bolts and flame-like spikes coming off of moving figures portrayed a fierce burst of movement but also served to make the figure a more dominant element in the composition. Another borrowed feature from commercially made cards was that of a target or scope. "I use the scope for a quarterback when he has to give it up. You know he has to like shoot the ball" Jay explained. Flames, spikes, bolts of lightening, radial designs, targets, and scopes were used to indicate speed and accuracy. Many of these commercial images represented in cards were appealing to the boys because of the dynamic quality of the designs and their visual appeal. Although the borrowed features were often cliches the boys learned the use of design elements and principles by using similar imagery in their cards.

The very first cards made by both boys incorporated simple printing. That is, the printing looked as if it were made by a child in elementary school. Anyone who were to sit down with Jay and Anton and listen to their story of making the card series would come to understand the extent to which they sequenced their own learning. As the series progressed they borrowed more difficult to master concepts. Slanting the simple printed text and outlining letters in color came 
before the boys actually began to experiment with making various typestyles and borrowing from more sophisticated styles in commercially made cards.

By pointing out to me all of the types of writing he does, Anton illustrated his growing ability as a graphic artist. He first described what he called normal letters and then what he referred to as autograph letters. Anton unfolded for me the history of his coming to have a vast repertoire of styles of lettering, borrowed and invented, from which to choose. Each type of lettering he described to me was a little more difficult to master than the last. In fact. Anton identified a total of twelve types of writing that he employed rather than the five he said he would name. Sometimes his journey led him to make discoveries by accident, as in the "fuzzy letters". As he made more cards, Anton could master more difficult concepts relating to typography and graphic design exhibited in commercially marketed trading cards. In charge of his artistic serial he demanded of himself increased mastery of the art of creating text and design.

I looked at a page of Anton's more recently made cards and noticed that none of the players were outlined in black or colored marker. Outlining had been the device used most often in the earlier cards to make players stand out. These outlined figures were clearly placed against a solid background. In his recently made cards the figures became more integrated into the space created by type and design. When I placed an old and a new card side by side I noticed similarities between the cards. Two cards had the same color scheme. Green, yellow and black were used predominantly. The older card was very flat, and the figure seemed separate from the background. It was as if there were two planes, a foreground and a background.

Rather than one plane being superimposed on another the more recent cards gave the illusion of space in which parts of the figure might be located on various points of the picture plane. Anton had colored in a black rectangular form behind the figure which let some of the text show through. The black form behind the figure created a deep space on the picture plane. If he had continued the green background behind the figure, the illusion of the figure integrated in the space would not have been created. In the newer card, principles of color theory were discovered and used in conjunction with the design and type of lettering used. Green was used to recede and yellow to advance on the picture plane. Although Anton used this principle of color theory on the older card as well, his black outline of the figure and the yellow outline detracted from the ability of the yellow to come forward on the plane.

Early cards often displayed a centrally balanced figure with the text layered on top, almost like a banner or nameplate. As the cards progressed, the figures were placed in every possible location within the confines of the rectangle, and the text was woven masterfully into the composition. The first cards often displayed the entire figure, but eventually the two boys became more daring with how they cropped the photographic image, and the figure's orientation in space became less conventional. 
Anton cropped and positioned the figure in his "Brian Reese" card in a fashion that cut the entire card diagonally in half. The photograph was cropped so severely that it was not obvious at first that the viewer was looking at a human form. A horizontal image placed across the top of the card intersected the diagonal force of the two arms reaching for the hoop. The hoop itseff was barely discernible. In this card, the photographic images were more abstract. Anton had created the impression of tremendous movement with the force and direction of the two diagonal shapes. He had cropped the photograph in such a way that the subject matter was less recognizable at first glance. This was not to say that Anton was not concerned with the recognizability of the subject matter. Rather, what may be indicated, was his appreciation of the shear force of the form created in the space. He seemed to become increasingly aware of the nature of form and design in his unfolding series.

Anton addressed formal components of making art when he pointed out various aspects of the cards he had made. When he made statements such as, "This is good because I like how this stands out, "he was paying attention to the functions of design and composition. How text, image and design worked together was of major concern to Anton, like a game he was learning to play well.

That Anton and Jay learned elements and principles of design in their unfolding series confirmed for me that students in the gifted art program could learn these concepts in self-defined projects that were personally meaningful and satisfying. I could have planned lessons that separated particular components of design and taught these concepts to Jay and Anton and the fifth and sixth grade students. But would I have been as successful teaching Jay and Anton these notions as they had been discovering them in the four months they worked on cards? When I talked to Jay and Anton about their cards they referred to aspects of their work that I recognized as design elements and principles of art When I used such terms to explain how I saw components of their works they understood what I was talking about and indicated this to me in their response.

\section{References}

Ingalls, Z. (1996). The language of images and words. The Chronicle of Higher Education. March 1, B5-B7. 